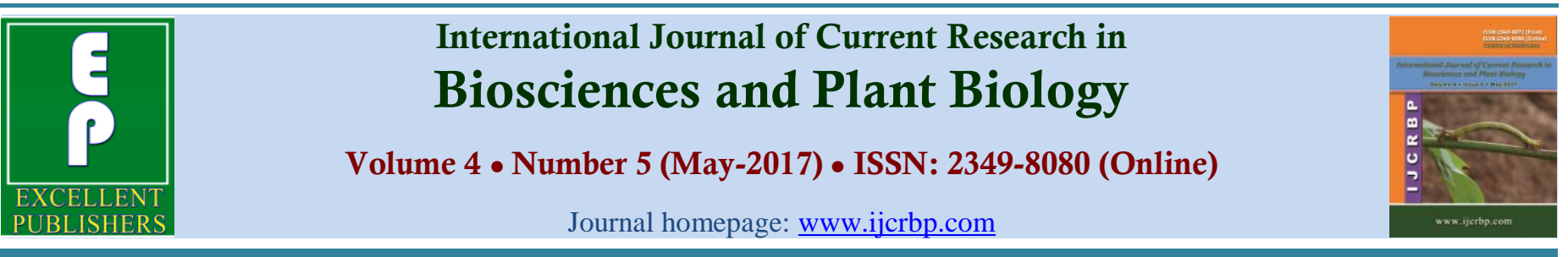

\title{
Effect of Co-Administration of Coenzyme Q10 with Metformin on Diabetic Albino Rats
}

\author{
Sonu Kumar ${ }^{1}$, Umashanker Prasad Keshri ${ }^{2 *}$, Manju Gari ${ }^{3}$ and Rajiv Kumar ${ }^{2}$ \\ ${ }^{1}$ PG Student, ${ }^{2}$ Associate Professor, ${ }^{3}$ Professor \& Head, Department of Pharmacology, Rajendra Institute of Medical Sciences, \\ Ranchi-834 009, Jharkhand, India
}

*Corresponding author.

\begin{abstract}
High blood glucose concentration degenerates vital tissues and it is correlated with diabetes and its complications. It generates free radicals by metal catalyzed oxidation of glucose, oxidative degeneration and by protein glycation. Therefore chronic antioxidant therapy may be useful in preventing the degenerative changes by free radical scavenging nature. In this way it may have the positive impact in protecting the tissue from further damaging effect of hyperglycemia. On this background the plan of this research work was made. Two groups of six healthy male albino rats weighting $150-250 \mathrm{~g}$ were used in this experiment. Diabetes was induced by freshly prepared single intraperitoneal injection of streptozotocin in the dose of $60 \mathrm{mg} / \mathrm{kg}$ body weight pretreated with nicotinamide intraperitoneally in a dose of $120 \mathrm{mg} / \mathrm{kg}$ body weight. First group was treated with metformin $45 \mathrm{mg} / \mathrm{kg}$ body weight and the $2^{\text {nd }}$ group by metformin in the same dose and coenzyme Q10 $1.8 \mathrm{mg} / \mathrm{kg}$ body weight concurrently once daily for 28 days. Fasting blood sugar was measured weekly till four weeks in morning hour. In the initial few weeks there was no difference in fasting blood sugar level but at the end of 4 week there was little more decrease in fasting blood sugar which was significant statistically. This shows that coenzyme Q10 have the positive impact in controlling the blood sugar level in mild diabetic rats probably due to its crucial antioxidant nature as add on drug with metformin.
\end{abstract}

\section{Article Info}

Accepted: 21 April 2017

Available Online: 06 May 2017

\section{Keywords}

Antioxidant

Coenzyme Q10

Diabetes mellitus

Metformin

\section{Introduction}

Coenzyme Q10 is a fat-soluble, vitamin-like quinone commonly known as ubiquinone, CoQ, and vitamin Q10 (Greenberg and Frishman, 1990; Tran et al., 2001). It is a ubiquitous compound vital to a number of activities related to energy metabolism and found in highest concentrations in tissues with high energy turnover such as the heart, brain, liver, and kidney. Coenzyme Q10 is vital for the proper transfer of electrons within the mitochondrial oxidative respiratory chain. Its main function is adenosine triphosphate production. Because dysfunctional energy metabolism has been cited as a contributing factor for a number of conditions, coenzyme Q10 has been indicated in the treatment of cardiac, neurologic, oncologic, and immunologic disorders. It has an antioxidant and lipid peroxidation preventing activity. It also indirectly stabilizes calcium channel to decrease calcium overload (Sugiyama et al., 1980; Nayler, 1980). 
It is used for treating congestive heart failure, angina, high blood pressure, diabetes mellitus, gum disease, breast cancer, Huntington's disease, Parkinson's disease, muscular dystrophy, increasing exercise tolerance, chronic fatigue syndrome, lyme disease, etc.

Coenzyme Q10 has been considered for improving glycemic control through various mechanisms, including a decrease in oxidative stress. Two earlier randomized controlled trails by Henriksen et al. and Eriksson et al. in 1999 using 100 to $200 \mathrm{mg}$ of coenzyme Q10 in patients with type 1 or 2 diabetes found no difference in glycemic control and insulin requirement. A more recent randomized controlled trial by Hodgson et al in 2002 using $200 \mathrm{mg}$ per day for 12 weeks found modest improvements in $\mathrm{A} 1 \mathrm{C}$ levels.

In a meta-analysis, Suksomboon et al. (2015) concluded that coenzyme Q10 supplementation has no beneficial effects on glycemic control, lipid profile or blood pressure in patients with diabetes. However, it may reduce triglycerides levels. Research about the effectiveness of coenzyme Q10 for diabetes is conflicting.

Literature support its important physiological role but research report related to its use in diabetes is contradictory. Supplementation of coenzyme Q10 may have the supportive role by supplying adequate energy and its antioxidant property and thus preventing and maintaining in normal physiology and functions of the cell related to glucose metabolism, aerobic respiration and ATP formation. Therefore the plan of this study was made to observe its effects and interaction as add on drug in streptozotocin induced diabetic rats.

\section{Materials and methods}

\section{Animals}

Healthy male rats weighing 150-250 grams were taken for the present study. Animals were acclimatized to the available housing condition and were fed with standard laboratory diet and water was given ad libitum. The experiment was conducted in accordance with ethical norms approved by institutional animal ethics committee guidelines.

\section{The details of groups}

Animals were divided in two groups, six animals in each group by random selection. One group of animals were treated with metformin (considered as group A or diabetic control group) and 2nd group was co administered metformin and coenzyme Q10 (considered as group B or diabetic treated group). The dose of metformin was decided $45 \mathrm{mg} / \mathrm{kg}$ body wt and coenzyme Q10 $1.8 \mathrm{mg} / \mathrm{kg}$ body wt according to the body surface area and previous research works report. The information related to drugs, and chemicals used in this experiment is as follows:

1. Tab. Coenzyme Q 10, $20 \mathrm{mg}(\mathrm{CoQ})$, Universal Medicare.

2. Tab. Metformin $500 \mathrm{mg}$ (Glycephage) FrancoIndian Pharmaceutical.

3. Inj. Streptozotocin $250 \mathrm{mg}$ powder, Himedia, Mumbai.

4. Nicotinamide $100 \mathrm{gm}$ powder, Animed, Kolkata.

5. Glucometer, Dr Morepen, Model BG 03

Rats were given different treatment orally once daily for 28 days in the morning hour by gavage tube.

\section{Induction of diabetes mellitus}

Diabetes was induced by freshly prepared single intraperitoneal injection of streptozotocin in the dose of $60 \mathrm{mg} / \mathrm{kg}$. Before streptozotocin injection, nicotinamide was injected intraperitoneally in a dose of $120 \mathrm{mg} / \mathrm{kg}$. After intraperitoneal injections animals were allowed to drink 5\% glucose solution overnight to overcome streptozotocin induced hypoglycemia (Sanders, 2002).

The fasting blood glucose level was determined after 72 hrs of streptozotocin injection. The rats having blood glucose level in between $200-250 \mathrm{mg} / \mathrm{dl}$ were used for the study. The diabetic animals were allowed free access to tap water, normal laboratory diet, and were maintained at room temperature in their cages.

Diabetes was confirmed after $72 \mathrm{hrs}$ of streptozotocin induction. Treatment was started on $8^{\text {th }}$ day from induction and was considered as day ' 0 '. The treatment was continued for 28 days. Blood samples were collected on day $0,7,14,21$ and $28^{\text {th }}$ day to determine the blood glucose level by glucometer.

\section{Biochemical analysis of blood sugar}

Blood samples were collected from the tail of rat. It was cleaned appropriately and was cut $0.5 \mathrm{~mm}$ with the help of sterilized blade to get one drop of blood to ooze out. It was allowed on the appropriate reaction zone of the strip. 
Fasting blood sugar on the display was noted down in the master chart. Betadine ointment was applied on the tail of each rat and cared to prevent any secondary infection.

\section{Statistical analysis}

Statistical analysis of data was carried out by employing analysis of variance. One way ANOVA test was used to compare the effect of drugs on different group. Tukey's HSD test was used for post-hoc analysis of significant overall differences (Park, 2013).

\section{Results and discussion}

Diabetic control (metformin treated) and diabetic treated group (metformin and coenzyme Q10 treated diabetic rats) both showed the decreasing pattern in blood glucose level in subsequent weeks and it achieved the normal physiological range in four weeks period. The hypoglycemic effect in diabetic treated group was found better than the control group and a sharp and significant fall in blood glucose level was observed in this group in four weeks period (Tables 1 and 2).

Table 1. Sequential changes in FBS in both groups throughout the study period. All the values are expressed as mean \pm standard deviation.

\begin{tabular}{lll}
\hline Period & Group A & Group B \\
\hline Day 0 & $206.50 \pm 1.87$ & $206.33 \pm 1.97$ \\
Day 7 & $183.83 \pm 2.93$ & $183.50 \pm 4.09$ \\
Day 14 & $160.83 \pm 3.49$ & $157.33 \pm 2.58$ \\
Day 21 & $130.83 \pm 3.49$ & $125.50 \pm 3.27$ \\
Day 28 & $86.00 \pm 2.37$ & $77.50 \pm 1.87$ \\
\hline
\end{tabular}

Table 2. The statistical comparison between Group A and Group B (Values for Group A and Group B are expressed as mean \pm standard deviation).

\begin{tabular}{llllll}
\hline & Day 0 & Day 7 & Day 14 & Day 21 & Day 28 \\
\hline Group A & $206.50 \pm 1.87$ & $183.83 \pm 2.93$ & $160.83 \pm 3.49$ & $130.83 \pm 3.49$ & $86.00 \pm 2.37$ \\
Group B & $206.33 \pm 1.97$ & $183.50 \pm 4.09$ & $157.33 \pm 2.58$ & $125.50 \pm 3.27$ & $77.50 \pm 1.87$ \\
Mean difference & 0.1667 & 0.3333 & 3.5000 & 5.33333 & 8.5000 \\
$p$-value & 1 & 1 & 0.311 & 0.074 & $0.000^{*}$ \\
\hline
\end{tabular}

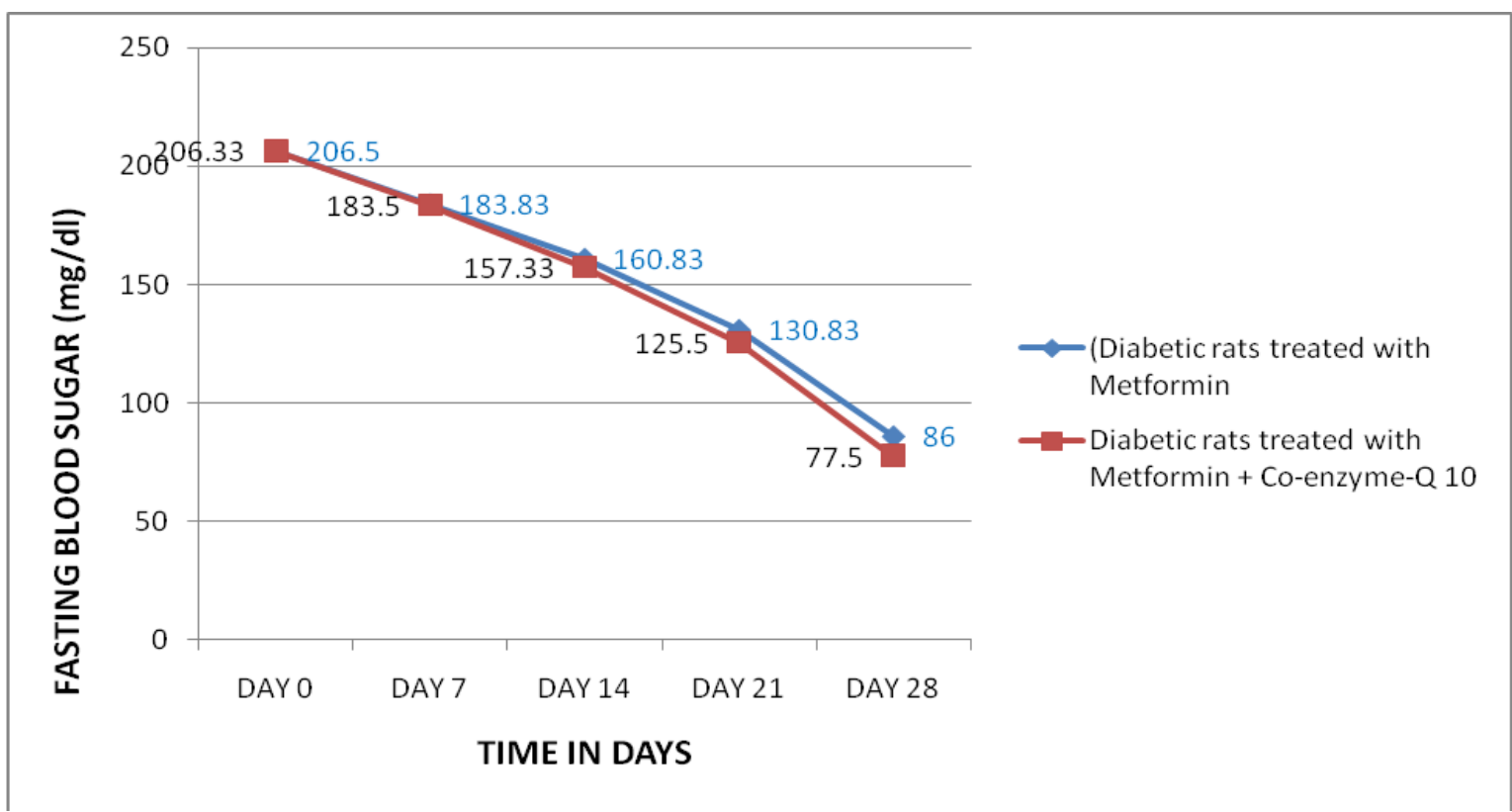

Fig. 1: Showing comparison of sequential changes in fasting blood sugar level among Group A and Group B.

Fig. 1 shows that the FBS of group A and group B start to decline together and merge with each other up to day 7. As the experimental period proceeds there is gradual separation of both the lines which is declining, 
line for group B has a more sharp fall compared to the group A and further, by $28^{\text {th }}$ days value of fasting blood sugar level shows statistically significant reduction in $p$ (0.00) value.

After streptozotocin induction all the animals developed hyperglycemia. On starting treatment of diabetic control group by metformin blood sugar was started decreasing and it was found significant reduction when compared within the group weekly. At the end of $4^{\text {th }}$ week the blood sugar level reached at normal physiological range.

Metformin improves glycemic control in diabetic condition. It is an antihyperglycemic drug. It decreases glucose levels by decreasing hepatic glucose production and by increasing insulin action in muscle and fat. It also decreases plasma glucose by reducing the absorption of glucose from the intestine. And these explain the glycemic control of diabetic rats treated by metformin (Davis, 2006).

Animals treated by Metformin with coenzyme Q10 have no significant difference in blood glucose level in initial three weeks ( $p$-value: 0.074 ) but it is significant at the end of four weeks.

In two different studies on streptozotocin-nicotinamide induced diabetic rats model Maheshwari and co-workers in 2014 and 2017 observed that adjuvant therapy of coenzyme Q10 with metformin and coenzyme Q10 with sitagliptin have more beneficial effect in reducing glycated hemoglobin level and protecting renal function in diabetic rats in comparison to sitagliptin or metformin administered alone. Synergistic antidiabetic effect of coenzyme Q10 with sitagliptin has pharmacodynamical resemblance with this study and it corroborates the potentiating glucose lowering effect of coenzyme Q10 with metformin.

Coenzyme Q10 is a component of the electron transport chain and participates in aerobic cellular respiration. It is an essential process used in the production of energy to sustain different organs through the production of adenosine triphosphate. Coenzyme Q10, therefore, plays a vital role in the efficiency of the electron transport chain and energy production (Lehninger, 1971; Beal, 2003; Ebadi et al., 2001). Ninety-five percent of the human body's energy is generated by this way (Ernster and Dallner, 1995; Dutton et al., 2000). Therefore, those organs with the highest energy requirements have the highest Coenzyme Q10 concentrations (Okamoto et al., 1989; Aberg et al., 1992; Shindo et al., 1994). Diabetes is a state of oxidative stress in which there is increased free radical damage to the beta cells of pancreas. The possible mechanism by which chronic use of coenzyme Q10 may be beneficial in diabetes is that in its reduced form, this molecule holds electrons loosely, so able to give up one or both electrons quite easily and, thus, works as an electron transporter in ATP synthesis by mitochondria (Bentinger et al., 2010). Coenzyme Q10 thereby helps in scavenging the free radicals and act as antioxidant that prevents further damage to the pancreatic beta cell.

\section{Conclusion}

On the basis of this study we can conclude that coenzyme Q10 on co administration with metformin on long term use potentiate its efficacy. Further detailed pharmacokinetic and pharmacodynamic studies in a greater sample size are needed to generate data related to the potentiating action of this drug.

\section{Conflict of interest statement}

Authors declare that they have no conflict of interest.

\section{References}

Aberg, F., Appelkvist, E.L., Dallner, G., Ernster, L., 1992. Distribution and redox state of ubiquinones in rat and,human tissues. Arch. Biochem. Biophy. 295(2), 230-234.

Beal, M.F., 2003. Bioenergetic approaches for neuroprotection in Parkinson's disease. Ann. Neurol. 53(3), 39-48.

Bentinger, M., Tekle, M., Dallner, G., 2010. Coenzyme $\mathrm{Q}$ biosynthesis and functions. Biochem. Biophys. Res. Commun. 396 (1), 74-79.

Davis, S.N., 2006. Insulin, oral hypoglycemic agents, and the pharmacology of the endocrine pancreas. In: Goodman \& Gilman's The Pharmacological Basis of Therapeutics (Ed.: Brunton, LL.). 11 ${ }^{\text {th }}$ Edn. McGraw-Hill Medical Publishing Division, New Delhi.

Dutton, P.L., Ohnishi, T., Darrouzet, E., Leonard, M.A., Sharp, R.E., Cibney, B.R., Daldal, F., Moser, C.C., 2000. 4 Coenzyme Q oxidation reduction reactions in mitochondrial electron transport. In: Coenzye Q: Molecular Mechanisms in Health and Disease (Eds.: Kagan, V. E., Quinn, P.J.), CRC Press, Boca Raton. pp.65-82. 
Ebadi, M., Govitrapong, P., Sharma, S., Muralikrishnan, D., Shavali, S., Pellett, L., Schafer, R., Albano, C., Eken, J., 2001. Ubiquinone (coenzyme q10) and mitochondria in oxidative stress of Parkinson's disease. Biol. Signals Recept. 10, 224-253.

Eriksson, J.G., Forsen, T.J., Mortensen, S.A., Rohde, M., 1999. The effect of coenzyme Q10 administration on metabolic control in patients with type 2 diabetes mellitus. Biofactors. 9, 315-318.

Ernster, L., Dallner, G., 1995. Biochemical, physiological and medical aspects of ubiquinone function. Biochim. Biophys. Acta. 1271(1), 195204.

Greenberg, S., Frishman, W.H., 1990. Co-enzyme Q10: A new drug for cardiovascular disease. J. Clin. Pharmacol. 30, 596-608.

Henriksen, J.E., Andersen, C.B., Hother-N. O., Vaag, A., Mortensen, S.A., Beck, N, H., 1999. Impact of ubiquinone (coenzyme Q10) treatment on glycaemic control, insulin requirement and well-being in patients with type 1 diabetes mellitus. Diabet. Med. 16, 312-318.

Hodgson, J.M., Watts, G.F., Playford, D.A., Burke, V., Croft, K.D., 2002. Coenzyme Q10 improves blood pressure and glycaemic control: A controlled trial in subjects with type 2 diabetes. Eur. J. Clin. Nutr. 56, 1137-1142.

Lehninger, A.L., 1971. The molecular organization of mitochondrial membranes. Adv. Cytopharmacol. 1, 199-208.

Maheshwari, R. A., Balaraman, R., Sen, A. K., Seth, A. K., 2014. Effect of coenzyme Q10 alone and its combination with metformin on streptozotocinnicotinamide-induced diabetic nephropathy in rats. Indian J. Pharmacol. 46(6), 627-632.
Maheshwari, R., Balaraman, R., Sen, A.K., Shukla, D., Seth, A., 2017. Effect of concomitant administration of coenzyme Q10 with sitagliptin on experimentally induced diabetic nephropathy in rats. J. Renal Failure. 39 (1), 130-139.

Nayler, W.G., 1980. The use of coenzyme Q10 to protect ischemic heart muscle. In: Biomedical and Clinical Aspects of Coenzyme Q (Eds.: Yamamura, Y., Folkers, K., Ito, Y.). Vol. 2. Elsevier, Amsterdam. pp.409-425.

Okamoto, T., Matsuya, T., Fukunaga, Y., Kishi, T., Yamagami, T., 1989. Human serum ubiquinol-10 levels and relationship to serum lipids. Int. J. Vitamin Nutr. Res. 59(3), 288-292.

Park, K., 2013. Park Text Book of Preventive and Social Medicine. $20^{\text {th }}$ Edn, Banarsidas Bhanot, Jabalpur. $172 \mathrm{p}$.

Sanders, L.J., 2002. From Thebes to Toronto and the $21^{\text {st }}$ century: An incredible journey. Diabet .Spect. 15, 56-60.

Shindo, Y., Witt, E., Han, D., Epstein, W., Packer, L., 1994. Enzymic and non-enzymic antioxidants in epidermis and dermis of human skin. J. Investig. Dermatol. 102(1), 122-124.

Sugiyama, S., Kitazawa, M., Ozawa, T., Suzuki, K., Izawa, Y., 1980. Anti-oxidative effect of coenzyme Q10. Experentia. 36, 1002-1003.

Suksomboon, N., Poolsup, N., Juanak, N., 2015. Effects of coenzyme Q10 supplementation on metabolic profile in diabetes: A systematic review and metaanalysis. J. Clin. Pharm. Therapeut. 40(4), 413-418.

Tran, M.T., Mitchell, T.M., Kennedy, D.T., Giles, J.T., 2001. Role of coenzyme Q10 in chronic heart failure, angina and hypertension. Pharmacotherapy. 21(7), 797-806.

\section{How to cite this article:}

Kumar, S., Keshri, U.P., Gari, M., Kumar, R., 2017. Effect of co-administration of coenzyme Q10 with metformin on diabetic albino rats. Int. J. Curr. Res. Biosci. Plant Biol. 4(5), 52-56.

doi: https://doi.org/10.20546/ijcrbp.2017.405.006 